\title{
INTERSUBJECTIVE POSITIONING IN POLITICAL AND ECONOMIC INTERVIEWS
}

\author{
Jana Kozubíková Šandová
}

\begin{abstract}
The aim of this paper is to examine linguistic means of intersubjective positioning used in the genre of interview, which is typically connected with establishing speaker's identity and position. The theoretical framework for this study is the Appraisal Theory proposed by Martin and White (2005), in concrete terms the category of Engagement, which enables us to analyse how speakers adopt and express their attitude not only to the proposition but also to a potential audience. Modal expressions modify the strength of the illocutionary force of propositions. Thus, intersubjective positioning overlaps with such concepts as hedging, boosting, evidentiality, and modality. A corpus of political and economic interviews will be analysed with the aim of investigating and comparing markers of intersubjective positioning, and further, of explicating their pragmatic functions.
\end{abstract}

\section{Key words}

Appraisal Theory, Engagement, intersubjective positioning, political interviews, economic interviews, speaker involvement

\section{Introduction}

"(Inter)subjectivity is concerned with the linguistic expression of the speaker's relation to textually referenced or allowed statements, assumptions and inferences" (Defrancq \& De Clerck 2011: 40). These are traditionally referred to as 'points of view'. As Defrancq and De Clerck state, many scholars consider the concept of 'points of view' being assigned to the hearer, whereas the term 'subjectivity' is reserved "for instances in which the statements, assumptions and inferences are the speaker's own" (ibid.: 40). In this sense, (inter)subjective positioning overlaps with hedging, boosting, evidentiality, and modality since hedging and boosting devices and expressions of modality modify the illocutionary force of utterances and hence show speaker involvement with the propositions expressed.

This paper attempts to analyse markers of intersubjective positioning, namely, modal and cognitive verbs and modal adverbs. The use of these expressions in the genre of political and economic interview is compared, and, also, their pragmatic functions are explicated. The theoretical framework for this study is Martin and White's model of the Appraisal Theory (Martin 2000, White 2003, Martin \& White 2005), or to be more specific, the category of Engagement. 
This theory is an approach focusing on the analysis of the language of evaluation and stance. It is a very convenient framework for this investigation since modality viewed from a broader perspective applied here is also crucial for the Appraisal Theory in that it includes various linguistic expressions employed by speakers to modify the strength of the illocutionary force and, at the same time, to express their attitude towards the propositions presented. This means that modal markers enable speakers to position themselves intersubjectively.

A corpus of political and economic interviews will be analysed since the genre of interview is typically connected with establishing the speaker's identity and position. The aim of this contribution is to investigate and compare linguistic choices of intersubjective positioning the speakers made, and further, to explicate pragmatic functions these markers perform in these two types of interviews.

The paper is structured as follows: Section 2 introduces the Appraisal Theory as proposed by Martin and White (2005). Since Engagement is the most important category of the Appraisal framework for this study, Section 3 focuses on it in greater detail. Methodology and the corpus of political and economic interviews used for this analysis are described in the following section. Sections 5 discusses the results of a quantitative analysis of the language material and adduces a number of illustrating examples from the corpus. And finally, Section 6 draws conclusions from the research.

\section{Appraisal theory}

TheAppraisal framework deals with expressions of intersubjective positioning, with the "interpersonal in language" (Martin \& White 2005: 1). It focuses on "the communicative and rhetorical functionality of those wordings by which speakers/ writers take a stance towards the various points-of-view and value positions being referenced by the text and thereby align themselves vis-à-vis those who hold, or are represented as holding, these positions" (ibid.: 260). It is concerned with the presence of speakers/writers in texts and expressing their attitudes both towards propositions they present and towards their putative audience. In other words, it deals with "how writers/speakers construe for themselves particular authorial identities or personae, with how they align or disalign themselves with actual or potential respondents, and with how they construct for their texts an intended or ideal audience" (ibid.: 1). Within this broader perspective, the framework examines a diverse group of lexico-grammatical means which are classified, simply said, into those which open up space for negotiation, and those which close down space for dialogic alternatives.

These issues have been touched upon by functionally and semiotically oriented approaches. The Appraisal Theory aims to develop the systemic 
functional theory formulated by M. A. K Halliday within Systemic Functional Linguistics (SFL), which understands language as a social semiotic system. SFL works with three metafunctions of language: the ideational, the interpersonal, and the textual. It is the interpersonal meaning that the proponents of Appraisal Theory aim to develop. They introduced three axes that show the variation of intersubjective stance.

The first one is called 'affect' and it has to do with attitudinal evaluations, which not only "reveal the speaker's/writer's feelings and values but also [...] their expression can be related to the speaker's/writer's status or authority as construed by the text" (Martin \& White 2005: 2). Additionally, they construct relationships between the author and potential audience. The second axis relevant to the variation of an intersubjective stance is traditionally called 'modality', or, more specifically, 'epistemic modality' and 'evidentiality'. In the Appraisal framework, not only concepts of certainty, involvement and knowledge are important but also "how the textual voice positions itself with respect to other voices and other positions" (ibid.). Last but not least, the third dimension of 'intensification' and 'vague language' is connected with speakers'/writers' modification of the force of their statements and of the semantic categorisations they use.

Martin and White (2005) further claim that in order to describe the communicative function of linguistic means of intersubjective positioning sufficiently, it is necessary to consider them as interactive and dialogic. In this regard, they have been influenced by Bakhtin's and Voloshinov's notions of dialogism and heteroglossia, whereby "all verbal communication, whether spoken or written, is 'dialogic' in that to speak or write is always to reveal the influence of, refer to, or to take up in some way, what has been said/written before, and simultaneously to anticipate the responses of actual, potential or imagined readers/listeners" (Martin \& White 2005: 92). This dialogic perspective enables us to reflect the degree to which speakers identify themselves with the positions of other speakers. Thus, Appraisal Theory makes it possible to explain how speakers/writers position themselves in interaction.

Speakers/writers may take up a neutral, positive or negative stance towards the propositions of others. At the same time, they may take into account a potential audience in that they pay attention to the reactions or responses of the addressees to the propositions expressed or try to anticipate these responses. Thus, the Appraisal framework focuses on whether "the value position is presented as one which can be taken for granted for this particular audience, as one which is in some way novel, problematic or contentious, or as one which is likely to be questioned, resisted or rejected" (ibid.: 93). 
Since this theory examines meaning in interaction, language means analysed are quite diverse. It does not pay attention to their grammatical forms but rather to communicative effects these means have when used in context. Thus, expressions traditionally termed as means of modality, evidentiality, attribution, etc. are examined within the Appraisal Theory. Also, language means used to modify the illocutionary force traditionally called intensifying and attenuation devices are investigated.

Taken from a wider perspective, Appraisal is regarded as one part of interpersonal semantics, together with negotiation and involvement. Appraisal itself consists of three interconnected domains: Graduation, Attitude and Engagement. "Attitude is concerned with our feelings, including emotional reactions, judgements of behaviour and evaluation of things. Engagement deals with sourcing attitudes and the play of voices around opinions in discourse. Graduation attends to grading phenomena whereby feelings are amplified and categories blurred" (ibid.: 35, emphasis in original). All three domains of Appraisal interact in communication.

\section{Engagement}

It is the aforementioned category of Engagement that is important for this study since it is concerned with linguistic means expressing dialogic positioning of the speaker or writer. Martin and White (2005) distinguish two basic types of Engagement: monoglossic and heteroglossic. Monoglossic statements are those which are not modified, as for instance:

(1) The European Central Bank has been putting more liquidity into the banking system of Europe. (W. Hague)

Heteroglossic assertions are modified by various linguistic expressions influencing the illocutionary force of utterances, e.g.:

(2) And I believe that what our troops did in Afghanistan and in Iraq is incredibly important in defeating that. (T. Blair)

As regards my corpus of political and economic interviews, most assertions were heteroglossic.

Martin and White (2005) divide Heteroglossic Engagement into two dialogic orientations contingent on the kind of intersubjective positioning: Dialogic Contraction and Dialogic Expansion. Dialogically contractive statements "are directed towards excluding certain dialogic alternatives from any subsequent communicative interaction or at least towards constraining the scope of these 
alternatives in the colloquy as it henceforth unfolds" (ibid.: 117). These statements are further divided into the categories Disclaim and Proclaim. Disclaim is associated with various linguistic means expressing negation (e.g. You don't have to get up before 6 o'clock to catch the 8.30 train.), concession or counter expectation (e.g. Although it was quite windy, it was not that cold.). When using some of these means, the speaker/writer positions himself in disagreement with an alternative viewpoint or rejects it. The category of Proclaim is connected with emphasizing the validity of the proposition. The information is presented as reliable and generally agreed to, thus excluding any alternative positions. There are three subcategories of Proclaim: Concur (involving expressions of agreement or supporting a certain view expressed in the text, e.g. of course, obviously, naturally), Pronounce (including emphasizing expressions of the author, e.g. I contend, we must agree that, there is no doubt that), and Endorse (the information contained in the proposition is assigned to a reliable external source, e.g. As $X$ has shown/demonstrated/ pointed out.).

As regards dialogically expansive statements, they open up "the dialogic space of alternative positions" (ibid.: 103). The category of Entertain includes "wordings by which the authorial voice indicates that its position is but one of a number of possible positions and thereby, to greater or lesser degrees, makes dialogic space for those possibilities. The authorial voice entertains those dialogic alternatives" (ibid.:104, emphasis in original). It involves language means traditionally labelled as expressions of epistemic modality (cf. Palmer 2001, Bybee \& Fleischman 1995, Coates 1983) and evidentiality (Chafe 1986), e.g. modal verbs (e.g. could, may, might, must), modal adverbs (e.g. probably, possibly, perhaps), cognitive verbs (e.g. I think, I believe, I suspect). Within Attribute, the second category of Dialogic Expansion, the presented information is "grounded in the subjectivity of an external voice" (Martin \& White 2005: 98). The speaker may either distance himself from this source ( $X$ claims that) or take a neutral stance ( $X$ said, according to $X$, in $X$ 's view).

\section{Corpus description and methods}

As already stated, the aim of this study is to analyse language means of intersubjective positioning from the point of view of the category of Engagement. Within this category, modality viewed from a wider perspective is of crucial importance because it involves all the linguistic means of modifying the illocutionary force of utterances and showing the attitude of speakers towards the propositions expressed. This broader view is also taken up in this study. It is in agreement with Simon-Vandenbergen's claim (1996: 391) that "modal expressions form an open-ended class" since any lexico-grammatical means used by speakers to show their attitude towards the proposition may be considered as modal expressions. 
The material under investigation is a corpus of political and economic interviews: specifically four interviews with British politicians totalling 4,459 words and two economic interviews having 4,786 words. The size of the whole corpus is thus 9,245 words. All six interviews discuss the topic of currency union in the EU and were released between 2011 and 2014. The transcripts of interviews with Tony Blair, William Hague and George Osborne were downloaded from the Andrew Marr Show archive, the Ed Balls interview was downloaded from his personal webpage. The interview with L. G. Smaghi, an ex-Member of the ECB, is accessible from the Financial Times interviews archive and the interview with David Vines, a Professor of Economics, is downloadable for the Vox talks archive.

In all interviews expressions of Engagement were identified with regard to the context in which they occur and divided into the particular categories of Dialogic Contraction and Dialogic Expansion. Then, their pragmatic functions were determined.

As the two sub-corpora are not identical in length (the difference is 327 words), a frequency per 1,000 words of each category of Engagement was counted. Then, the results of the quantitative analysis were interpreted with the intention of comparing linguistic choices of intersubjective positioning of the speakers.

\section{Discussion of the results}

The linguistic means of Heteroglossic Engagement appear, to a greater or lesser extent, in all analysed interviews. The total number of these means in the whole corpus is 392, which means that their frequency per 1,000 words is 42 words. Politicians used more means of Heteroglossic Engagement than economists (236:156, which is 53:33 in normalised figures per 1,000 words, cf. Table 1).

\begin{tabular}{|c|c|c|c|}
\hline $\begin{array}{c}\text { Heteroglossic } \\
\text { Engagement }\end{array}$ & Political interviews & $\begin{array}{c}\text { Economic } \\
\text { interviews }\end{array}$ & Total \\
\hline Dialogic Expansion & 114 & 112 & $\mathbf{2 2 6}$ \\
\hline Dialogic Contraction & 122 & 44 & $\mathbf{1 6 6}$ \\
\hline Total (raw counts) & 236 & 156 & $\mathbf{3 9 2}$ \\
\hline Total (per 1,000 words) & $\mathbf{5 3}$ & $\mathbf{3 3}$ & $\mathbf{4 2}$ \\
\hline
\end{tabular}

Table 1: Categories of Heteroglossic Engagement 
As far as the category of Dialogic Contraction is concerned, it is less frequent than that of Dialogic Expansion (166:226). This frequency discrepancy is connected with the genre of the interview itself, which is inherently dialogic and opens up space for other perspectives and discussion of facts. However, if we take a closer look at the results of this research, we may see differences between the two types of interviews under analysis.

In general, politicians utilized more means of Heteroglossic Engagement than economists (236:156), which is connected with their need to assert themselves in front of the audience, to sound persuasive and influence the opinions of their potential voters. Dialogically contractive propositions are much more frequent in politicians' interviews ( 27 words per 1,000 words), who present their assertions as categorical with a limited space for further negotiation. In contrast, economists used an insignificant number of dialogically contracted propositions (nine words per 1,000 words). Economists do not aim at asserting their claims in front of the listeners as much as politicians do. Instead, they explain the facts more comprehensibly. These two equally persuasive strategies are relevant to different discourse domains examined.

What is interesting is the minimal difference in occurrence of dialogically expansive and dialogically contracted propositions in politicians' interviews (114:122), a larger contrast between these two categories has been expected. A study conducted on a similar topic (cf. Downing \& Perucha 2013) shows a higher difference in frequency between these two categories. They explain a higher incidence of dialogically contractive propositions in political interviews as a sign of "high subjective involvement of the speaker towards the information conveyed and more contracted space of other alternatives" (ibid.: 390).

In spite of a not so substantial difference between Dialogic Contraction and Dialogic Expansion revealed in this study, a high degree of speaker involvement is a typical feature of political interviews (cf. Fetzer 2011, Kozubíková Šandová 2014). This slight difference between Contraction and Expansion in my corpus may also be influenced by the topic of the interviews, namely, monetary union within the EU. Politicians aim at giving as clear statements as possible, so that the addressees understand advantages and disadvantages of it better. They try to open up the dialogic space for more alternatives and discussion. If we investigated pre-election debates, for instance, the results of the research might be different. Politicians would use more dialogically contracted statements since they are much more 


\section{- Politicians Economists}

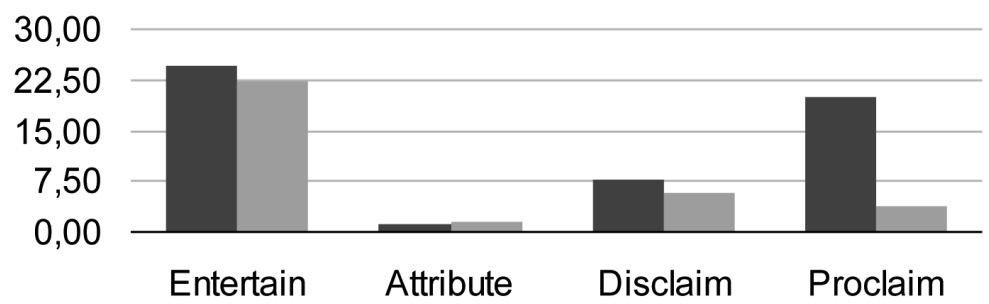

Figure 1: Heteroglossic Engagement (frequency per 1,000 words)

\subsection{Categories of Dialogic Contraction}

As already mentioned, Dialogic Contraction involves two subcategories, Disclaim and Proclaim. The occurrence of Disclaim with economists and politicians is very similar (27:34). The differences emerge if we compare the second category, that of Proclaim. It appears in political discussions much more frequently. In concrete terms, the frequency in political interviews is 20 per 1,000 words and with just four words in economic interviews (cf. Figure 1). Politicians attempt to sound convincing and powerful in their propositions, to present them as reliable and well-founded with almost no space for further arguments. Again, this indicates a high degree of speaker involvement. This, however, is not the case with economists, who rely on more dialogically expansive statements.

(3) Today I strongly agree with the Treasury analysis and the view of the Permanent Secretary that a currency union between an independent Scotland and the rest of the UK would be bad for Scotland and bad for the rest of the United Kingdom. I, as a Chancellor, could not sign up to an agreement which I knew would be bad for Scotland and bad for taxpayers across the rest of the UK. (E. Balls)

In (3), several instances of Proclaim may be found. The speaker expresses his strong agreement with two important authorities that do not agree with a currency union between an independent Scotland and the rest of the UK. This firm agreement may influence the audience fundamentally - or, at least the speaker wants the audience to be influenced by his personal opinion - and does not open space for further arguments much. Thus, the intersubjective positioning of the speaker is quite strong. At the same time, he makes use of evaluative 
adjectives, which also contributes to a high degree of speaker commitment to the proposition.

Similar statements also appear in (4). The politician expresses his confidence about not joining the Euro very explicitly and directly. He wants to sound very convincing in front of the audience and influence it in his own direction.

That's a key reason why we should never join the euro. I'm absolutely clear about that. So I very strongly agree with that argument. (W. Hague)

Regarding pragmatic functions of Dialogic Contraction in economic interviews, they are a bit different from those in political discourse. Economists do not attempt to influence the listeners in the way politicians do, but they just take up a stance towards the issues they are explaining, as in (5), where the economist clarifies how difficult the situation in some European countries is as regards the monetary union. They do not sound as authoritative as politicians. In this connection, Martin and White (2005: 117) point out that Proclaim is regarded as a reinforcement of the speaker's position and Disclaim is connected with expressing contrast and negation, which is valid both for politicians and economists.

Q: So how serious, David, do you think the issue of contagion still is within the Eurozone? For example, we've seen in recent weeks that apart from the crisis in Portugal and Ireland, Spain and even Italy are being downgraded. Would you agree that there's an issue here?

A: It's very hard to be in a monetary union in Europe, which is so asymmetric. The North, led by Germany, is recovering after the financial crisis and growing. (D. Vines)

In (6), the economist explains his viewpoint concerning monetary union. He again says what he thinks is related and relevant to this topic and as a result, he sounds trustworthy.

(6) [...]. We're identifying that the European project really does require a much greater degree of federal management of the problems, and central, more than political, leadership of the European project. Let's focus on two things: Fiscal discipline, the fiscal way in which Europe's managed is going to have to change. (D. Vines)

The category of Disclaim comprises linguistic means directly rejecting some dialogic alternative, "or [this alternative] is represented as not applying" (Martin \& White 2005: 117). As mentioned, Denials and Concession/Counter- 
expectation are distinguished within Disclaim. The latter domain is represented by expressions such as but, although, even though, however, etc., as illustrated by (7) and (8) occurring in the domain of political interviews.

(7) [...] We can do things in a different way and a fairer way, but if Scotland chooses independence that will cost jobs and growth in Scotland, it will lead to higher interest rates, and the idea that the rest of the UK and the next Labour Chancellor would say, well, ok, we'll sign up to higher interest rates and higher taxes too, to make that happen. (E. Balls)

(8) I think it's the biggest challenge for Europe since it began actually, since the European Union began. I think there's never been a tougher time to be a leader than right now. (T. Blair)

\subsection{Categories of Dialogic Expansion}

Both categories of Expansion, namely, Entertain and Attribute, are represented in the analysed interviews but with a different occurrence. Entertain is, for obvious reasons, much more frequent, as is evident from Figure 1 above. Within this category, the proposition is represented "as grounded in its own contingent, individual subjectivity" (Martin \& White 2005: 98). The domain of Attribute is used by speakers only when they report someone else's statement, as illustrated by (9) and (10) below. It is not used much by both politicians and economists, which means that they rely on themselves when stating some facts rather than on somebody else's claims.

(9) Alex Salmond is saying to people that you can have independence and keep the pound and the Bank of England. That is not going to happen. It would be bad for Scotland, it would place an unacceptable burden on the UK taxpayer, it would repeat the mistakes of the euro area. (E. Balls)

(10) It looked like the ECB ended up having negative net worth. This really bizarre pincer movement developed where the rating agency said "If there's haircut, or some kind of write-down on Greek debt, then we'll declare Greece in default." And the European Central Bank says, "And when that happens we will be forced, as a matter of logic, to remove our financial support both for Greece and the Greek banking system. [...]." (D. Vines)

Entertain is represented almost evenly in the material under investigation. However, what is different is the incidence of its subclasses in the interviews. Linguistic means of Entertain were divided into four subcategories according to what functions they express (cf. Table 2). 
Intersubjective Positioning in Political and Economic Interviews

\begin{tabular}{|c|c|c|c|}
\hline Category & Politicians & Economists & TOTAL \\
\hline Cognition & 11.2 & 3.6 & $\mathbf{7 . 2}$ \\
\hline Possibility & 5.4 & 5.9 & $\mathbf{5 . 6}$ \\
\hline Certainty & 0.7 & 4.6 & $\mathbf{2 . 7}$ \\
\hline Obligation & 7.2 & 8.1 & $\mathbf{7 . 7}$ \\
\hline TOTAL & $\mathbf{2 4 . 4}$ & $\mathbf{2 2 . 1}$ & $\mathbf{2 3 . 3}$ \\
\hline
\end{tabular}

Table 2: Entertain - subcategories (frequency per 1,000 words)

A high occurrence of Cognition in politicians is connected with the frequency of appearance of the parenthetical I think, which is, again, an indication of subjective involvement of the speaker. Jucker (1986: 149) maintains that the function of $I$ think in political interviews is to avoid responsibility and to remain vague. Similarly, Simon-Vandenbergen (2000) states that "vagueness, achieved by various means, is then interpreted as a face-saving device: if you do not commit yourself to the truth of your claim, you cannot be accused later of having lied or of having been mistaken" (ibid.: 44). However, Aijmer et al. (2006) point out that $I$ think sometimes expresses epistemic uncertainty, but "more often [it] operates as a conversational routine or even as a way of individualising one's propositions in an authoritative way" (ibid.: 109). In this connection, White and Sano (2006) state that 'the more 'automatic' the use of a particular linguistic item in a given context [...], then the less meaning will be carried by its presence in the text. It is plausible, therefore, that, in comparison with other 'entertain' values, I think is to some degree desemanticised and accordingly does not so strongly convey dialogistic expansiveness as the other options" (ibid.: 201).

(11) I think it's the biggest challenge for Europe since it began actually, since the European Union began. I think there's never been a tougher time to be a leader than right now. I think the decisions are immensely difficult, but they've got to be taken because failure to take the decisions is also a form of decision with consequence. So I think right now for the single currency, it's absolutely essential if it is to be preserved, that the whole weight of Europe, its institutions come behind it. And I think you've got to have a long-term framework of credibility behind any short-term decision [...]. (T. Blair)

In (11), the speaker uses the parenthetical I think in almost every utterance of this turn. It demonstrates a high degree of involvement with the facts expressed, which is further augmented by frequent use of evaluative phrases (underlined). 
Apart from I think, other expressions of Cognition found in the interviews are: I mean, I believe, I suspect and I don't think, as illustrated in examples below.

(12) The idea that Alex Salmond could hope to be credible as an international figure, negotiating with the European Union or the UK government, while he makes threats which are so irresponsible he would renege on debt. I don't think that's taken seriously because if it was true it would be utterly catastrophic. (E. Balls)

(13) I think in a curious way, it's the speed with which you have to do it that's the problem. I mean one of the things I believe is that actually what the single currency crisis has done in a way is exposed the need for reform and accelerated... (T. Blair)

(14) The market is quite sceptical about that happening, and I suspect a lot of my time over the next few weeks is going to be with other European finance ministers and others talking about how we try and help the Greeks get through this situation. (G. Osborne)

Cognition does not occur in economic interviews very often, if compared to its frequency with politicians. Linguistic means within Entertain in economic interviews express most frequently Obligation (frequency 8.1 per 1,000 words). Obligation is expressed by the modals should, have to, need to and cannot in the corpus, with should indicating an action as desirable, need and have to expressing inevitable necessity to do something, and cannot showing difficulties in doing an action.

Q: Is it your expectation that banks will use these funds to buy sovereign bonds? A: It is a first step. We have to see whether this will be enough to invert the trend of widening yields spreads, especially at the short end of the curve. (L.B. Smaghi)

[...] I think what governments need to do is, when they agree something, they should implement it rapidly and efficiently and not change their minds a few months later. (L.B. Smaghi)

Linguistic means expressing Obligation fulfil the same function in political interviews. However, Obligation with the modal verb should was not used so frequently. Obligation represented by have to or need to was more frequent, which may be a sign of urgency.

Q: Yeah, I'm asking you whether it's a likely outcome.

A: Well I'm not ... I don't think it would be helpful for me to say whether it's likely or not likely. We want an end to the uncertainty. Yes we have prepared contingency plans if we need to help British nationals who are there in any way. We keep those up to date on a daily basis. (W. Hague) 
(18) Q: Are we taking part in that one?

A: Well we are reluctant participants in that because we are a member of the European Union. There is a loan likely to come from the European Union. I didn't sign up to that approach. It was something signed up to my predecessor, Alistair Darling, but you know we have to live with that. (G. Osborne)

(19) I think, you know if you're looking at the very long-term and assume the Euro stabilises, we should certainly always keep the option open of doing it, but right now we've got our own ... we've got our own issues to look at too because you know we face the same delicate balance that everyone else does. (T. Blair)

As far as Possibility is concerned, it almost has the same frequency of use with politicians and economists. It is expressed by the modals can/could, may, and by the adverbials maybe and likely in the corpus. When using these linguistic means, speakers do not want to take full responsibility for their assertions and want to have a certain degree of detachment from their statements. They are not certain about the validity of their propositions. Rather, they leave some space for further alternatives, as in (20), (21) and (22) below. What is more, the dialogic approach reveals that the use of modality may not consist only in speakers' uncertainty about the validity of their claims but may stem from speakers' assumptions about their receivers' response.

(20) Q: Is it not time to think seriously about introducing 'eurobonds' to build fiscal solidarity between euro area countries?

A: This is a political choice that needs to be taken by the people of Europe. I am not sure it would necessarily be the most efficient solution for euro area public finances. Maintaining the discipline of markets with respect to national budgets may lead to better outcomes than an integrated or federal budget. I am not sure the US Federal budget is in a better shape than the euro area fiscal position. I could nevertheless envisage a limited amount of joint and several issuance to finance, for instance, specific projects, pan-European infrastructure or a common bank restructuring fund. (L.B. Smaghi)

(21) $Q$ : And yet here ...

A: And that is ... You know the fact we can ... (Marr tries to interject) ... we're going to talk about local election results, electoral reform, maybe we're going to talk about the House of Lords. (G. Osborne)

(22) Well we are reluctant participants in that because we are a member of the European Union. There is a loan likely to come from the European Union. I didn't sign up to that approach. It was something signed up to my predecessor, Alistair Darling, but you know we have to live with that. [...] (G. Osborne) 
Interestingly, the linguistic means of Certainty in economic interviews occur more frequently than those of Cognition. At the same time, the linguistic means of Certainty in political interviews are insignificant with a mere three occurrences. This may be connected with the fact that politicians do not want to present their statements as categorical because they want to save face in front of their listeners so that they cannot later accused of lying. Economists, on the contrary, are not under such pressure so they can afford to make assertions showing confidence about their claims.

(23) Once they've done that it's very important that we as politicians spell out to the people of the UK, including Scotland, but also the rest of the UK what the consequences of independence would be and we're honest about the choices which will be faced. I don't think that Alex Salmond and Nicola Sturgeon are being honest with the Scottish people when they say Scotland can keep the pound because they must know it is not true. (E. Balls)

Q: What future is there for the City of London as Europe's financial centre?

A: The euro has benefited London's financial centre. It is in the interest of the latter that the euro succeeds. The EU, and the ECB, would certainly contribute to help Britain if London was in difficulty. (L.B. Smaghi)

\section{Conclusion}

This paper has focused on an analysis of linguistic means of intersubjective positioning appearing in political and economic interviews. The category of Engagement of the Appraisal Theory has been used as a theoretical framework for this study. The contrastive analysis of a corpus of political and economic interviews totalling 4,459 words has revealed differences both in the use and distribution of these means.

Political interviews show a higher incidence of dialogically contractive statements than economic interviews, which is connected with the aim of politicians to assert themselves in front of the audience, to show involvement with the facts presented, and, also to close down the dialogic space for further negotiation. A frequent use of expressions of Proclaim by politicians may be attributed to their attempt to establish their identity and position. Economists, on the contrary, tend to be more receptive in this respect and open up space for other alternatives and discussion, which is also proven by the high number of dialogically expansive propositions.

Taking a closer look at the categories of Entertain, one can see that Cognition appears most frequently in politicians and Obligation is the most recurrent category in economic interviews. Cognitive verbs in economic interviews 
indicate speaker subjective involvement with the messages conveyed, while in the case of politicians it is an expression of their political beliefs. Markers of Obligation demonstrate the necessity of doing something desirable or appropriate. Another category of Entertain appearing in the corpus is Possibility. It shows speaker detachment from his/her statements and not taking full responsibility for speaker's claims. At the same time, when using means of Possibility, politicians show uncertainty and want to leave space for other options and save face in front of their audience in order not to be accused of lying. This fact correlates with the use of markers of Certainty, which are almost completely absent in political interviews. Economists, conversely, use more certainty markers since they are in a different communicative situation than politicians and make assertions showing confidence quite freely.

Intersubjective positioning of politicians connected with an attempt to influence the audience is also evident if we examine the interaction of pronominal forms with Engagement markers. Unfortunately, due to the limited extent of this paper, I cannot go into details. However, preliminary research has shown that co-occurrence of personal pronouns and Engagement markers appears more frequently in political interviews (102 instances, compared to 27 appearances in economists' interviews). An extensive use of the pronoun $I$ in politicians again indicates a high degree of subjectivity and involvement with their propositions. Compared to an occasional incidence of this pronoun, economists' assertions do not focus on self-presentation to such an extent as politicians' claims do. These intermediate results corroborate with contrastive analysis of Engagement markers described above. However, a valid interpretation of the ways intersubjective positioning is constructed is not possible without taking into account interactions between the devices used, e.g. between modal verbs and their agents, which are expressed not only by pronominal expressions but also by other language means.

On the whole, the results of this study are consistent with a similar analysis of Downing and Perucha (2013), who claim that "the use and distribution of stance markers of modality and pronominal forms seem to correlate with differences in the way that speakers construct their public identities. These different representations are, in turn, in accordance with the particular aims of their social/political group" (ibid.: 408). In the case of politicians, it is a positive selfpresentation and legitimization of their political position and power. In the case of economists, it is drawing attention to specific economic issues, an explanation of their advantages and disadvantages, and taking up a stance towards the problems they clarify. 
However, what is also important to stress is the limited extent of the corpus examined in this study. Therefore, it is not possible to generalise too much since the low number of speakers could allow for the possibility of idiosyncratic use.

\section{References}

Aijmer, K., Foolen, A., and Simon-Vandenbergen, A.-M. (2006) 'Pragmatic markers in translation: A methodological proposal.' In: Fischer, K. (ed.) Approaches to Discourse Particles. Amsterdam: Elsevier. 101-114.

Bybee, J. and Fleischmanm, S. (1995) 'Modality in grammar and discourse.' In: Bybee, J. and Fleischman, S. (eds) Modality in Grammar and Discourse. Amsterdam and Philadelphia: John Benjamins.

Chafe, W. (1986) 'Evidentiality in English conversation and academic writing.' In: Wallace, C. and Nichols, J. (eds) Evidentiality: The Linguistic Encoding of Epistemology. Norwood, NJ: Ablex Publishing Corporation. 261-272.

Coates, J. (1983) The Semantics of the Modal Auxiliaries. London and Canberra: Croom Helm.

Defrancq, B. and De Clerck, B. (2011) 'Intersubjective positioning in French and English. A contrastive analysis of 'ca dépend'and 'it depends'. In: Aijmer, K. (ed.) Contrastive Pragmatics. Amsterdam and Philadelphia: John Benjamins. 40-71.

Downing, L. H. and Perucha, B. N. (2013) 'Modality and personal pronouns as indexical markers of stance: Intersubjective positioning and construction of public identity in media interviews.' In: Marín-Arrese, J. I., Carretero, M., Arůs Hita, J. and van der Auwers, J. (eds) English Modality: Core, Periphery and Evidentiality. Mouton de Gruyter. 379-410.

Fetzer, A. (2011) 'I think this is I mean perhaps this is too erm too tough a view of the world, but I often think ...': Redundancy as a contextualization device.' Language Sciences 33/2, 255-267.

Jucker, A. (1986) News Interviews. Amsterdam and Philadephia: John Benjamins.

Kozubíková Šandová, J. (2014) Speaker Involvement in Political Interviews. Frankfurt am Main: Peter Lang.

Martin, J. R. (2000) 'Beyond exchange: Appraisal systems in English.' In: Hunston, S. and Thompson, G. (eds) Evaluation in Text: Authorial Stance and the Construction of Discourse. Oxford: Oxford University Press. 142-175.

Martin, J. R. and P. R. R. White (2005) The Language of Evaluation: Appraisal in English. Houndmills: Palgrave Macmillan.

Palmer, F. R. (2001) Mood and Modality. Cambridge: Cambridge University Press.

Simon-Vandenbergen, A.-M. (1996) 'Image-building through modality: The case of political interviews.' Discourse and Society 7/3, 389-415.

Simon-Vandenbergen, A.-M. (2000) 'The functions of $I$ think in political discourse.' International Journal of Applied Linguistics 10/1, 41-63.

White, P. R. R. (2003) 'Beyond modality and hedging: A dialogic view of the language of intersubjective stance.' Text 23/2, 259-284.

White, P. R. R. and Sano, M. (2006) 'Dialogistic positions and anticipated audiences: A Framework for stylistic comparisons.' In: Aijmer, K. and Simon-Vandenbergen, A.M. (eds) Pragmatic Markers in Contrast. Amsterdam: Elsevier. 191-214. 


\section{Sources}

Balls, E. (2014) Ed's Interview on Currency Union. 13 February, 2014. http:/www. edballs.co.uk/blog/?p=4830.

Blair, T. (2011) Tony Blair Interview. 13 November, 2011. BBC News. http://news.bbc. co.uk/2/hi/programmes/andrew marr show/9638498.stm.

Hague, W. (2012) William Hague Interview. 19 February, 2012. BBC News. http://news. bbc.co.uk/2/hi/programmes/andrew_marr_show/9697684.stm.

Osborne, G. (2011) George Osborne Interview. 10 May, 2011. BBC News. http://news. bbc.co.uk/2/hi/programmes/andrew_marr_show/9479525.stm.

Smaghi, L. B. (2011) FT Interview Transcript: Lorenzo Bini Smaghi. 22 December, 2011. Financial Times. http://www.lorenzobinismaghi.com/documents/interviste/ 2011/2011\%2012\%2023\%20-\%20FT\%20-\%20LBS_transcript.pdf.

Vines, D. (2011) The Eurozone Crisis: Greek Recovery and the Challenges of Asymmetric Monetary Union. 5 August, 2011. VOX. http://www.voxeu.org/vox-talks/eurozonecrisis-greek-recovery-and-challenges-asymmetric-monetary-union.

Jana Kozubíková Šandová is Assistant Professor of English Linguistics at the University of South Bohemia in České Budějovice, Czech Republic. Her research interests include topics on the interface between pragmatics and semantics, e.g. pragmatic functions of linguistic means in political interviews, intersubjective positioning in political and scientific discourse. Her latest publications deal with pragmatic aspects of political discourse.

Address: Mgr. Jana Kozubíková Šandová, Ph.D., Department of English, Faculty of Education, University of South Bohemia, Jeronýmova 10, 37115 České Budějovice, Czech Republic. [e-mail: sandova@pf.jcu.cz] 